\title{
INTERDISCIPLINARIDADE - DESAFIO PARA O SISTEMA EDUCACIONAL BRASILEIRO
}

Irene Antônia de Mouraㅜ; Adriana dos Santos Prado Sadoyama²; Geraldo Leal Sadoyama ${ }^{3}$

\section{Resumo}

Este trabalho aborda o tema Interdisciplinaridade - um desafio para o sistema educacional brasileiro. As transformações sociais e a situação atual da educação no Brasil vêm estabelecendo mudanças curriculares e das práticas pedagógicas, além de reformas políticas e institucionais tanto no Ensino Fundamental, quanto no Superior exigindo dos educadores e gestores mais conhecimento levando-os a uma ampla discussão sobre essa temática, uma vez que terão que rever sua práxis e desenvolver um trabalho interdisciplinar nas instituições educacionais. Para isso é necessário que o sistema educacional brasileiro aceite o desafio, saia do comodismo e pesquise meios de trabalhar as habilidades $e$ competências comuns das disciplinas, sem fragmentá-las possibilitando 0 envolvimento de toda a comunidade escolar, formando parcerias dentro e fora da escola. Trazendo para as instituições não somente a inovação tecnológica, mas a inovação na forma de atuar em sala de aula, reorganizando os espaços e atividades escolares favorecendo ao educando maior interação com o que está sendo ensinado. Com a finalidade de aprofundar sobre 0 tema

1 - Mestranda no curso de Gestão Organizacional pela Universidade Federal de Goiás. Campus Catalão. irene.antoniademoura@gmail.com

2 - Docente da Universidade Federal de Goiás - Regional de Catalão. Professora do Mestrado profissional em Gestão Organizacional. Doutora em Letras e formação em Pedagogia. drisadoyama@gmail.com.

3 - Docente da Universidade Federal de Goiás - egional de Catalão. Professor do Mestrado Profissional em Gestão Organizacional. Doutor em Imunologia e Parasitologia aplicadas. gsadoyama@gmail.com. 
Interdisciplinaridade, políticas públicas $e$ as propostas de mudanças estabelecidas para as instituições educacionais, aspectos relevantes sobre esse tema, e como o Brasil vencerá esse grande desafio de implantar verdadeiramente essa metodologia nas unidades escolares foi realizada uma revisão bibliográfica para elaborar essa pesquisa. Espera-se por meio desse trabalho verificar se alguma instituição já conseguiu implementar de forma prática e eficaz tal procedimento metodológico e quais foram as estratégias utilizadas.

Palavras Chave: Interdisciplinaridade. Educação. Sistema educacional 